\title{
Ethacrynate Sodium
}

National Cancer Institute

\section{Source}

National Cancer Institute. Ethacrynate Sodium. NCI Thesaurus. Code C47993.

The sodium salt form of ethacrynic acid, an unsaturated ketone derivative of aryloxyacetic acid without a sulfonamide substituent belonging to the class of loop diuretics. Ethacrynic acid is extensively bound to plasma proteins; both ethacrynic acid in its unchanged form as well as its metabolites are excreted in bile and urine. 